\title{
Potentiation by Halogen Compounds of the Lethal Action of $\gamma$-Radiation on Spores of Bacillus cereus
}

\author{
By G. W. GOULD \\ Unilever Research Laboratory, Colworth House, Sharnbrook, Bedford \\ (Accepted for publication 22 October 1970)
}

SUMMARY

\begin{abstract}
Spores of Bacillus cereus were inactivated by $\gamma$-radiation more effectively in the presence than in the absence of a variety of halogen compounds. Where homologous series of compounds were used, activity decreased in the order $\mathrm{I}>\mathrm{Br}>\mathrm{Cl}$ and $\mathrm{F}$. Activity did not depend upon affinity of the compounds for thiol groups. Potassium iodate was the most active compound tested. Iodate and iodoacetamide (IAM), and to a lesser extent iodide, were most effective at low $\mathrm{pH}$ values, but potentiation by 3,5-diiodo-Ltyrosine was hardly affected by $\mathrm{pH}$ value. Survivor curves of spores irradiated in water plus IAM or iodate were convex, suggesting that potentiation increased with increase in $\gamma$-radiation dose. The compounds tested were all more effective potentiators of radiation inactivation of spores in water than in sodium phosphate buffers or in complex medium, and potentiation was greater with low than with high spore concentrations. Histidine antagonized the potentiation of radiation inactivation by iodate, iodide and iodoacetamide. Potentiation decreased with decrease in temperature, and was not shown at $-15^{\circ}$. The results suggest that potentiation resulted from toxicity to spores of halogen-free radicals, and to a lesser extent free halogen, formed by reaction of the compounds with the radiolytic products formed from water during irradiation.
\end{abstract}

\section{INTRODUCTION}

Iodoacetamide (IAM) potentiated the lethal action of ionizing radiation for some vegetative bacteria, including the remarkably radiation-resistant Micrococcus radiodurans (Dean \& Alexander, I962), by a mechanism which probably depended on formation of free radicals from the IAM (Dewey \& Michael, 1965). Other halogen compounds (e.g. iodoacetic acid (Bridges, 1962), iodide (Dean \& Alexander, 1965), other halides (Matsuyama, Namiki \& Okazawa, I967)), were also capable of potentiating the lethal action of ionizing radiation for vegetative bacteria, though little work of this nature has been done with bacterial spores. Apart from interest in the mechanisms of action, there are practical reasons for studying such potentiators. For instance, radiation preservation of foodstuffs and other perishable materials would become a more practical possibility if the necessary doses could be diminished: selective sensitization of malignant mammalian cells to radiation could be an important aid to therapy. These reasons, and paucity of data concerning the mechanism of spore resistance to ionizing radiation, prompted this study of some compounds found to potentiate the $\gamma$-radiation inactivation of spores. 


\section{METHODS}

Spores. Bacillus cereus strain PX was grown for 3 days at $30^{\circ}$ on the surface of agar containing potato extract (Difco, $0.4 \%, \mathrm{w} / \mathrm{v}$ ), yeast extract (Difco, $0.4 \%, \mathrm{w} / \mathrm{v}$ ) and glucose $(0.25 \%, \mathrm{w} / \mathrm{v}), \mathrm{pH} 7 \cdot 3$. The free spores were washed off the agar, cleaned by centrifuging six times from distilled water and stored in water at a concentration of about $20 \mathrm{mg}$. equiv. dry wt $/ \mathrm{ml}$. at $4^{\circ}$.

Chemicals were 'Analar' grade or were the purest obtainable from British Drug Houses Ltd, Poole, Dorset, or Koch-Light Laboratories Ltd, Colnbrook, Buckinghamshire. Thyroid hormone analogues were obtained from Nutritional Biochemicals Corp., Cleveland, Ohio, U.S.A.

Viable counts. Samples ( $\mathrm{I} \mathrm{ml}$.) were washed out of ampoules into $9 \mathrm{ml}$. amounts of L-cysteine solution (IO $\mathrm{mM}$ ) then further decimally diluted in sterile distilled water. The cysteine was included to quench the thiol reagents used in some experiments and prevent them being carried over into the poured plates of yeast glucose agar used for viable counts. Colonies were counted after incubation of plates for 2 days at $37^{\circ}$.

Radiation was from a ${ }^{60} \mathrm{Co}$ source which irradiated samples at a dose rate of about $0.8 \mathrm{Mrad} / \mathrm{h}$. at about $20^{\circ}$ unless otherwise stated. Samples (I ml.) for irradiation were sealed in glass ampoules so that, with the high doses used, irradiation was essentially anoxic over the range studied. Control samples bubbled with $\mathrm{N}_{2}$ or sealed in vacuo were used to ensure that residual $\mathrm{O}_{2}$ did not contribute to the observed effects of potentiators. Samples were held on ice when not being irradiated, and were used within about $3 \mathrm{~h}$. of the termination of irradiation. Unirradiated controls were always included in experiments and showed no fall in viable count unless stated in Results.

\section{RESULTS}

Potentiation of the lethal effect of $\gamma$-radiation on Bacillus cereus spores by various chemicals

Table I summarizes the effects of a number of chemicals on the destruction of Bacillus cereus spores by $\gamma$-radiation. The following points are of interest. (I) A number of chemicals which potentiated the lethal action of radiation on spores in water failed to do so effectively in buffer (see particularly iodoacetic acid, iodoacetamide, bromide and iodide, bromate and iodate). (2) Numerous bromine and iodine compounds were potentiators, but the thiol reactants $p$-chloromercuribenzoic acid $(p \mathrm{CMB})$ and $N$ ethylmaleimide (NEM) were not. (3) Where series of halogen compounds were used, the iodine derivatives were more effective than the bromine, and the chlorine and fluorine derivatives were relatively ineffective (see chloro-, bromo- and iodoacetic acids; fluoride, chloride, bromide and iodide; chlorate, bromate and iodate). (4) Benzoic acids with $o-, m$ - or $p$-iodine substituents were about equally effective. (5) Tyrosine had little effect on the radiation inactivation, but iodine-containing derivatives of it, and related thyroid hormone analogues were moderately active, especially L-thyroxine in water. (6) Iodate was the most effective potentiator found.

The strong antagonism by sodium phosphate buffer of the potentiation caused by IAM was obvious when radiation dose:survivor curves were studied (Fig. I, 2). Potentiation caused by iodide and iodate was much less affected by the buffer. When spores were irradiated in a rich medium (heart infusion broth) the potentiation was 
largely lost, apart from a slight increase in slope of the survivor curve when iodate was present (Fig. 3). It was also noticed that the amount of potentiation differed with different spore crops, and was clearly greater with fresh well-cleaned spores than with poorly cleaned suspensions or suspensions that had been stored for long periods.

Fig. 4 shows that the inactivation of spores even at low concentrations was only slightly influenced by the thiol reactants $p C M B$ and NEM at doses up to I Mrad, whereas IAM significantly increased the inactivation rate.

\title{
Table I. Inactivation by $\gamma$-radiation of spores of Bacillus cereus suspended in different reagents
}

\begin{abstract}
Reagents were used at a concentration of I mM except iodobenzoic acid at $0 \cdot 1 \mathrm{mM}$. Spores $\left(\mathrm{r} \cdot 5 \times 10^{8} / \mathrm{ml}\right.$.) were suspended in sodium phosphate solution (10 mM; $\left.\mathrm{pH} 7 \cdot 0\right)$ or in water as indicated in the table. The $\gamma$-radiation dose was $0.6 \mathrm{Mrad}$. $N$-Bromosuccinimide (I mM) killed unirradiated control spores in sodium phosphate $(4 \cdot 1 \%$ survivors) during the experimental period. The other reagents did not affect viability of unirradiated spores.
\end{abstract}

\begin{tabular}{|c|c|c|}
\hline \multirow{2}{*}{ Reagent } & \multicolumn{2}{|c|}{ Spores $(\%)$ surviving irradiation } \\
\hline & $\begin{array}{l}\text { Phosphate } \\
\text { solution }\end{array}$ & Water \\
\hline Control (no addition) & $2 \cdot 28$ & $2 \cdot 87$ \\
\hline Acetamide & $2 \cdot 84$ & - \\
\hline Chloroacetic acid & $1 \cdot 27$ & 0.54 \\
\hline Trichloroacetic acid & I $\cdot 88$ & - \\
\hline Bromoacetic acid & $2 \cdot 36$ & 0.085 \\
\hline Iodoacetic acid & $\mathrm{I} \cdot 25$ & 0.036 \\
\hline Iodoacetamide & $I \cdot 4 I$ & 0.0001 \\
\hline L-Tyrosine & $\mathrm{I} \cdot 24$ & $\mathrm{I} \cdot 6 \mathrm{r}$ \\
\hline DL-Thyronine & I.04 & 0.57 \\
\hline L-Thyroxine & I.04 & 0.045 \\
\hline 3,5,3'-Triiodo-L-thyronine & $2 \cdot 38$ & 0.29 \\
\hline 3,5-Diiodo-L-tyrosine & $0 \cdot 38$ & 0.42 \\
\hline$o$-Iodobenzoic acid & $2 \cdot 24$ & 0.34 \\
\hline$m$-Iodobenzoic acid & $\mathbf{I} \cdot 88$ & 0.52 \\
\hline$p$-Iodobenzoic acid & $1 \cdot 65$ & 0.49 \\
\hline p-Chloromercuribenzoic acid & $\mathrm{I} \cdot 04$ & $I \cdot 23$ \\
\hline$N$-Ethylmaleimide & 0.58 & $I \cdot 40$ \\
\hline$N$-Bromosuccinimide & 0.0065 & $<0.00001$ \\
\hline Potassium fluoride & 一 & $2 \cdot 13$ \\
\hline Potassium chloride & - & $2 \cdot 83$ \\
\hline Sodium bromide & 0.45 & 0.034 \\
\hline Potassium iodide & 0.23 & 0.068 \\
\hline Potassium chlorate & $4 \cdot 30$ & 2.56 \\
\hline Sodium bromate & $2 \cdot 70$ & 0.024 \\
\hline Potassium iodate & 0.012 & $<0.00001$ \\
\hline
\end{tabular}

The effect of concentration of three of the most effective potentiators in water is shown in Table 2. $N$-Bromosuccinimide was not as toxic alone as it was in buffer (see Table I). Table 2 emphasizes that iodate was more effective than bromate and that concentrations as low as $0.0 \mathrm{Im}$ significantly potentiated the lethal action of radiation. 


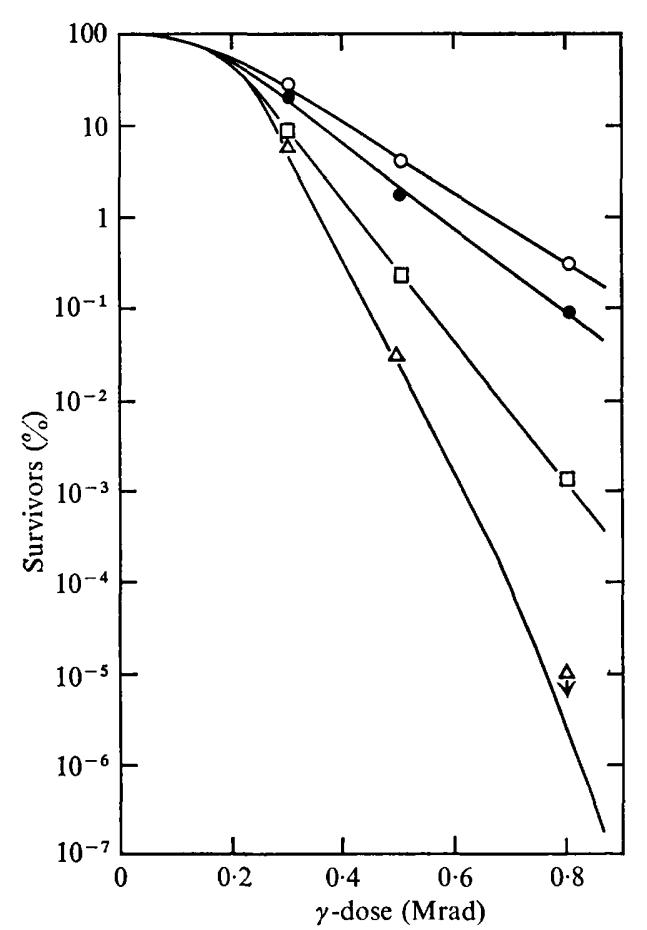

Fig. I

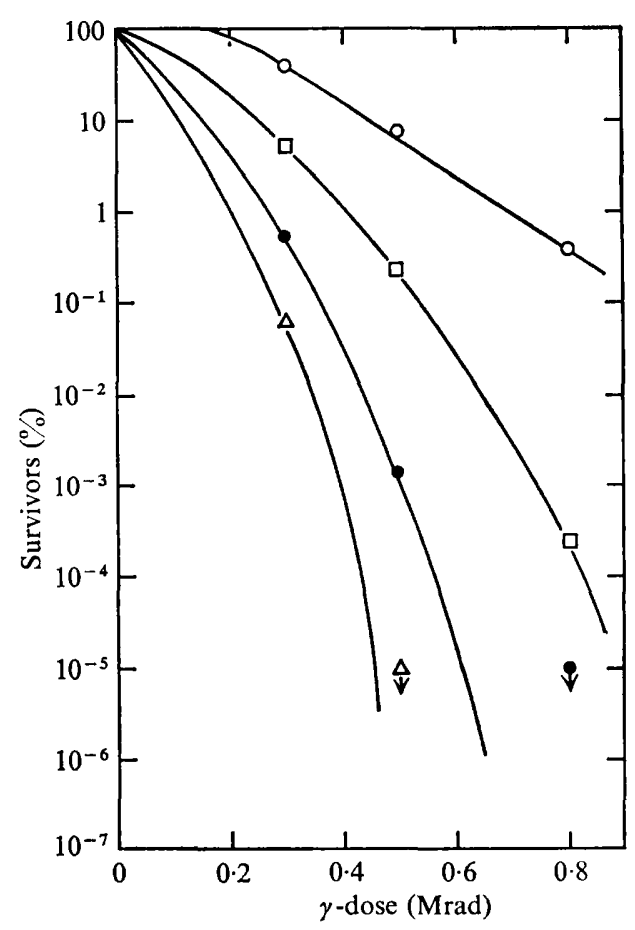

Fig. 2

Fig. I. Dose:survivor curves of spores of Bacillus cereus $\gamma$-irradiated in sodium phosphate solution (IO mM; $\mathrm{pH} \mathrm{7.0),} \mathrm{to} \mathrm{which} \mathrm{was} \mathrm{added:} \mathrm{iodoacetamide} \mathrm{(I} \mathrm{mM)} \mathrm{(O),} \mathrm{potassium}$ iodide ( $\mathrm{I} \mathrm{mM})(\square)$, potassium iodate (I mM) $(\triangle)$, control, no addition (O). Arrows indicate that counts were below the level shown by the symbol.

Fig. 2. Dose:survivor curves of spores of Bacillus cereus $\gamma$-irradiated in water instead of buffer as in Fig. I. Symbols as in Fig. I.

Effect of iodoacetamide and spore concentration on inactivation of spores with $\gamma$-radiation

The effect of iodoacetamide (IAM) present during irradiation on the shape of radiation dose:survivor curves of Bacillus cereus PX spores varied according to the spore concentration. This is shown in Fig. $5(a-c)$, in which initial spore concentrations of $1 \cdot 5 \times 10^{10}, 1.5 \times 10^{8}$ and $1.5 \times 10^{6}$ per ml. were used respectively. Spores in the most concentrated suspension were hardly influenced by even IO mM IAM (Fig. 5a), whereas spores at lower concentrations were clearly more readily killed when IAM was present (Fig. $5 b, c$ ). Even $0.1 \mathrm{mM}$ IAM strongly increased the radiation kill when the spore concentration was only $1.5 \times 10^{6}$ per ml. (Fig. $5 \mathrm{c}$ ). The apparent synergism of IAM and radiation depended more on the radiation dose than on the IAM concentration over the range studied. In addition to steepening the survivor curves, IAM caused them to become convex (Fig. $5 b, c$ ). This suggested that the apparent synergism of IAM with $\gamma$-radiation depended on some function which increased with increase in radiation dose. The same pattern of response was seen when potassium iodate was used as potentiator. 


\section{Absence of spore inactivation by 'carried over' iodoacetamide and iodate}

The possibility existed that the increased slopes of survivor curves in Fig. $5(b, c)$ were due to inhibition of colony formation caused by potentiator carried over with the diluted spore suspensions into the plates used for counting. To investigate this,

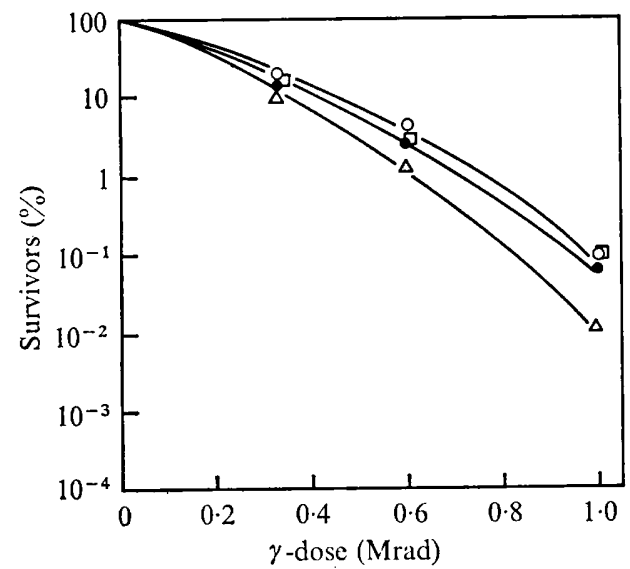

Fig. 3

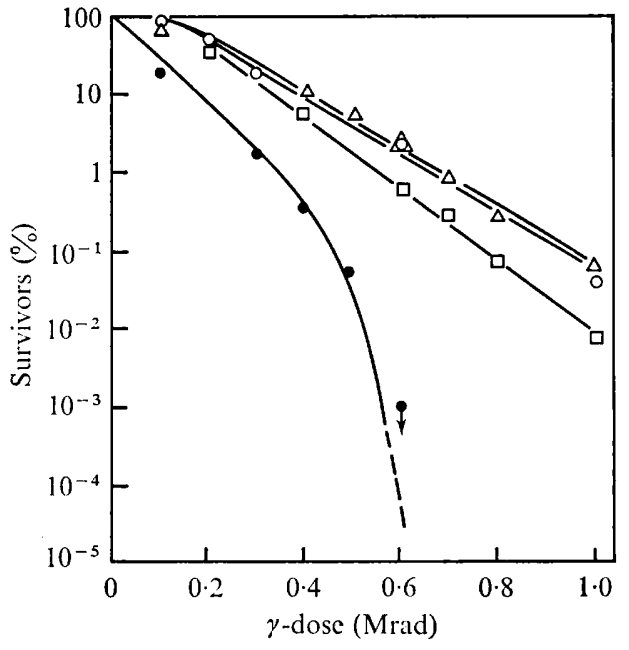

Fig. 4

Fig. 3. Dose: survivor curves of spores of Bacillus cereus $\gamma$-irradiated in heart infusion broth to which was added (I $\mathrm{mm}$ ) iodoacetamide (๑), potassium iodide ( $\square$ ), potassium iodate $(\triangle)$, control, no addition $(O)$.

Fig. 4. Dose:survivor curves of spores of Bacillus cereus $\gamma$-irradiated in water containing reagents for thiol groups. The concentration of spores was $1 \cdot 5 \times 10^{6} / \mathrm{ml}$. (I mM); $\square, p$-chloromercuribenzoic acid (1 mM, pH value to $7 \cdot 0$ with $\mathrm{NaOH}$ ); $\triangle, N$-ethylmaleimide (1 mM); $O$, control (no addition). Arrow indicates that the counts were below the level shown by the symbol.

Table 2. Effect of concentrations of potassium iodate, sodium bromate and $N$-bromosuccinimide on inactivation by $\gamma$-radiation of spores of Bacillus cereus

Spores $\left(1.5 \times 10^{8} \mathrm{ml}\right.$.) were suspended in water or in aqueous solutions of the reagents for irradiation. Unirradiated control suspensions retained full viability in the presence of the reagents. The $\gamma$-radiation dose was $0.6 \mathrm{Mrad}$.

\section{Reagent}

Control (no addition)

Potassium iodate

Sodium bromate

$N$-Bromosuccinimide

\section{Concentration}

(mM)

-

0.01

$\mathrm{I} \cdot \mathrm{O}$

0.01

$0 \cdot 1$

$\mathrm{I} \cdot \mathrm{O}$

0.01

0.1

I.O

\section{Spores surviving} radiation

(\%)

$2 \cdot 87$

0.85

0.087

$<0.00001$

2.94

$2 \cdot 43$

0.024

I. 24

0.84

$<0.00001$ 
control spores and spores which had been $\gamma$-irradiated at a dose of $0.6 \mathrm{Mrad}$ were incorporated into yeast glucose agar plates containing different concentrations of IAM or $\mathrm{KIO}_{3}$. The numbers of colonies which grew when the plates were incubated (Table 3) showed that these potentiators in the plates were not inhibitory to control or irradiated spores as long as their concentrations did not exceed about 10 $\mu \mathrm{M}$ IAM or I $\mathrm{mM} \mathrm{KIO}_{3}$. As these concentrations were not exceeded in any of the plates during the experiments described, it was concluded that the observed synergism of these compounds with $\gamma$-radiation was not due to carry-over.
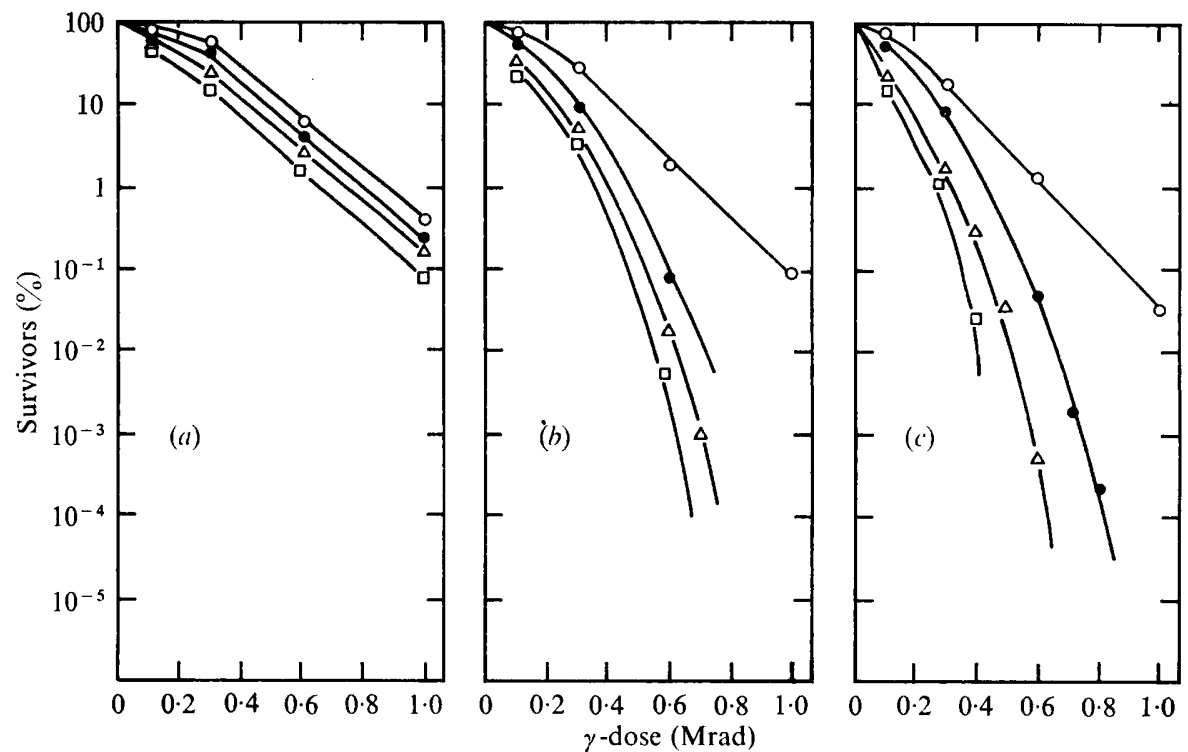

Fig. 5. Influence of iodoacetamide on inactivation of different concentrations of spores of Bacillus cereus by $\gamma$-radiation. Spore concentrations were (a) $\mathrm{I} \cdot 5 \times 10^{10} / \mathrm{ml}$., (b) $1 \cdot 5 \times 10^{8} / \mathrm{ml}$,, (c) $1.5 \times 10^{6} / \mathrm{ml}$. Concentrations of iodoacetamide present during irradiation of the aqueous spore suspensions were nil $(O), 100 \mu_{\mathrm{M}}(\bullet)$, I mM $(\triangle)$, I0 $\mathrm{mM}(\square)$.

\section{Table 3. Effect of iodoacetamide in the medium on viability of control and $\gamma$-irradiated spores of Bacillus cereus}

Poured plates were made from yeast glucose agar containing different concentrations of iodoacetamide or potassium iodate and about 150 viable spores per plate. The irradiated spores had been $98 \%$ inactivated by a dose of $0.6 \mathrm{Mrad}$.

Colony count (\%) following incubation in medium containing

\begin{tabular}{|c|c|c|c|c|}
\hline \multirow{2}{*}{$\begin{array}{l}\text { Concentration } \\
\text { of potentiator } \\
\text { in the medium }\end{array}$} & \multicolumn{2}{|c|}{ Iodoacetamide } & \multicolumn{2}{|c|}{ Potassium iodate } \\
\hline & $\begin{array}{l}\text { Unirradiated } \\
\text { spores }\end{array}$ & $\begin{array}{l}\text { Irradiated } \\
\text { spores }\end{array}$ & $\begin{array}{l}\text { Unirradiated } \\
\text { spores }\end{array}$ & $\begin{array}{l}\text { Irradiated } \\
\text { spores }\end{array}$ \\
\hline IO $\mu_{\mathrm{M}}$ & $84 \cdot 3$ & 104 & II 3 & 104 \\
\hline $\mathrm{I} 00 \mu_{\mathrm{M}}$ & $70 \cdot 8$ & $18 \cdot 8$ & 123 & 96 \\
\hline I $\mathrm{mM}$ & 0 & 0 & II9 & $64 \cdot 5$ \\
\hline $10 \mathrm{mM}$ & 0 & 0 & 0 & 0 \\
\hline
\end{tabular}


Role of leakage products in protecting high spore concentrations from $\gamma$-radiation plus IAM

Since irradiated spores are known to leak material including calcium, dipicolinic acid, amino acids and peptides (Farkas \& Kiss, 1965) it was possible that high spore concentrations were less susceptible to radiation plus IAM because of leakage of protective substances. To test this, spores of Bacillus cereus at a concentration of $\mathrm{r} \cdot 5 \times$ ${ }^{10} 10 / \mathrm{ml}$. were first irradiated in water at $0.6 \mathrm{Mrad}$ and then centrifuged. Fresh spores at the lower concentration of $1.5 \times 10^{8} / \mathrm{ml}$. were then suspended in the supernatant from the irradiated thick suspension and irradiated at $0.6 \mathrm{Mrad}$ in the presence or absence of I mM IAM. Table 4 shows that the supernatant from the irradiated dense suspension protected the less-dense suspension from the lethal effect of radiation plus IAM. (The low overall recovery from samples containing supernatant was due to some germination (about $70 \%$ ) which occurred during preparation.)

\section{Table 4. Protective effect of leakage products on the lethal action of $\gamma$-radiation plus iodoacetamide on spores of Bacillus cereus}

Spores $\left(1.5 \times 10^{8} / \mathrm{mll}\right.$.) were suspended in water or in supernatant fluid from an irradiated ( $0.6 \mathrm{Mrad}$ ) dense spore suspension $\left(\mathrm{I} \cdot 5 \times 10^{10} / \mathrm{ml}\right.$.). The $\gamma$-radiation dose was $0.6 \mathrm{Mrad}$. Iodoacetamide concentration was I mM.

\section{Suspending fluid}

Water

Supernatant from irradiated dense suspension

\begin{tabular}{|c|c|}
\hline \multicolumn{2}{|c|}{ Spores $(\%)$ surviving irradiatio } \\
\hline $\begin{array}{l}\text { In absence } \\
\text { of IAM }\end{array}$ & $\begin{array}{c}\text { In presence } \\
\text { of IAM }\end{array}$ \\
\hline $\mathbf{I} \cdot 04$ & 0.032 \\
\hline 0.47 & 0.470 \\
\hline
\end{tabular}

\section{Effect of $p H$ value on effectiveness of the potentiators}

The three potentiators iodoacetamide, iodide and iodate were all more effective at low than at high $\mathrm{pH}$ values (Table 5), though the relative effect of $\mathrm{pH}$ value was different for each reagent and effectiveness of the thyroid hormone analogue 3,5-diiodoL-tyrosine was hardly $\mathrm{pH}$-dependent. Control spores were more radiation-sensitive at low than at high $\mathrm{pH}$. When spores were irradiated with iodide or iodate in a rich medium in place of buffers, the increased effect at low $\mathrm{pH}$ values was lost (Table 6). Indeed, the potentiators were now less effective at low than at high $\mathrm{pH}$ values, though this was partly due to germination (resulting in enhanced radiosensitivity) of spores in the rich medium at higher $\mathrm{pH}$ values during the experiment.

\section{Antagonism of potentiators by histidine: role of iodine and long-lived radiation products}

To quench any iodine, and probably also any iodine-based free radicals formed during irradiation, histidine was included with some samples (Schramm, I964). The results (Table 7) showed that histidine indeed antagonized action of the three potentiators tested, suggesting involvement of iodine or halogen-based free radicals.

Iodine itself killed spores in the absence of radiation during a similar time-temperature regime to that undergone by the irradiated spores (Table 8) and, like irradiation in the presence of some of the potentiators (Table 5), was more lethal at low than at high $\mathrm{pH}$ value. 
Aqueous solutions of $\mathrm{IAM}, \mathrm{KI}$ and $\mathrm{KIO}_{3}(\mathrm{I} \mathrm{mM})$ irradiated alone at $0.6 \mathrm{Mrad}$ were not toxic when inoculated with Bacillus cereus spores $\left(1 \cdot 5 \times 10^{8} / \mathrm{ml}\right.$.) and incubated for up to $24 \mathrm{~h}$. at room temperature, suggesting that any major toxic irradiation products were short-lived.

Table 5. Influence of pH value on destruction of spores of Bacillus cereus by $\gamma$-radiation in the presence of iodine compounds in buffers

Spores $\left(\mathrm{I} \cdot 5 \times 10^{8} \mathrm{ml}\right.$.) were suspended in sodium phosphate solutions (10 mM) with or without the reagents and $\mathrm{pH}$ values adjusted with $\mathrm{HCl}$ or $\mathrm{NaOH}$. The radiation dose was $0.6 \mathrm{Mrad}$.

\section{Reagent}

Control (no addition)

Iodoacetamide (I mM)

Potassium iodide (I $\mathrm{mm}$ )

Potassium iodate (I mM)

Potassium iodate $(0 \cdot 1 \mathrm{mM})$

3,5-Diiodo-L-tyrosine ( $\mathrm{I} \mathrm{mM)}$
Spores (\%) surviving radiation in buffer at

$\begin{array}{rccl}\mathrm{pH} 3.0_{3.0} & \mathrm{pH} 5.0 & \mathrm{pH} \mathrm{7.0} & \mathrm{pH} \mathrm{9.0} \\ 0.300 & 1.440 & 3.940 & 5.800 \\ <10^{-4} & 0.0004 & 0.170 & 0.650 \\ <10^{-4} & 0.025 & 0.100 & 0.079 \\ & <10^{-4} & <10^{-4} & 0.00076 \\ 0.016 & 0.07 \mathrm{I} & 0.069 & 0.046 \\ 0.450 & 0.590 & 0.460 & 0.220\end{array}$

Table 6. Influence of $p H$ value on destruction of spores of Bacillus cereus by $\gamma$-radiation in the presence of potassium iodide or iodate in a rich medium

Spores $\left(1 \cdot 5 \times 10^{8} / \mathrm{ml}\right.$.) were suspended in heart infusion broth adjusted to the $\mathrm{pH}$ values shown with $\mathrm{HCl}$ and containing $\mathrm{KI}$ or $\mathrm{KIO}_{3}$ at $\mathrm{I} \mathrm{mm}$. The radiation dose was $0.6 \mathrm{Mrad}$.

\section{Reagent}

Control (no addition)

Potassium iodide

Potassium iodate
Spores $(\%)$ surviving radiation in broth at

$\begin{array}{cccc}\text { pH } 4.0 & \text { pH } 5.0 & \text { pH 6.0 } & \text { pH 7.0 } \\ 4.23 & 8.00 & 0.54 & 0.120 \\ 4.65 & 5.20 & 0.79 & 0.040 \\ 2.30 & 3.62 & 0.23 & 0.007\end{array}$

Table 7. Antagonism by histidine of the potentiating action of iodine compounds on inactivation of Bacillus cereus spores by $\gamma$-radiation

Spores $\left(1.5 \times 10^{8} / \mathrm{ml}\right.$.) were suspended in water containing the reagents \pm histidine (10 $\left.\mathrm{mm}\right)$. The radiation dose was $0.6 \mathrm{Mrad}$.

$\begin{array}{lcc}\begin{array}{c}\text { Reagent and } \\ \text { concentration }\end{array} & \begin{array}{c}\text { Histidine } \\ \text { present } \\ \text { or absent }\end{array} & \begin{array}{c}\text { Spores (\%) } \\ \text { surviving } \\ \text { radiation }\end{array} \\ \text { Control (no addition) } & \text { Absent } & 2.800 \\ & \text { Present } & 2.600 \\ \text { Iodoacetamide (I mM) } & \text { Absent } & 0.0001 \\ & \text { Present } & 1 \cdot 570 \\ \text { Potassium iodide (I mM) } & \text { Absent } & 0.068 \\ & \text { Present } & 1.000 \\ \text { Potassium iodate (O. I mM) } & \text { Absent } & 0.085 \\ & \text { Present } & 0.900\end{array}$




\section{Potentiation of radiation inactivation at different temperatures}

Spores of Bacillus cereus in water were inactivated by $\gamma$-irradiation more or less similarly at $-15^{\circ}, 2^{\circ}$ and $30^{\circ}$. However, when spores were irradiated in potassium iodate solutions, temperature had a much greater effect on inactivation. The potentiating action of iodate was completely suppressed in the frozen samples at $-15^{\circ}$ (Fig. 6a), and measurably less intense at $2^{\circ}$ than at $30^{\circ}$ (Fig. $6 b, c$ ).
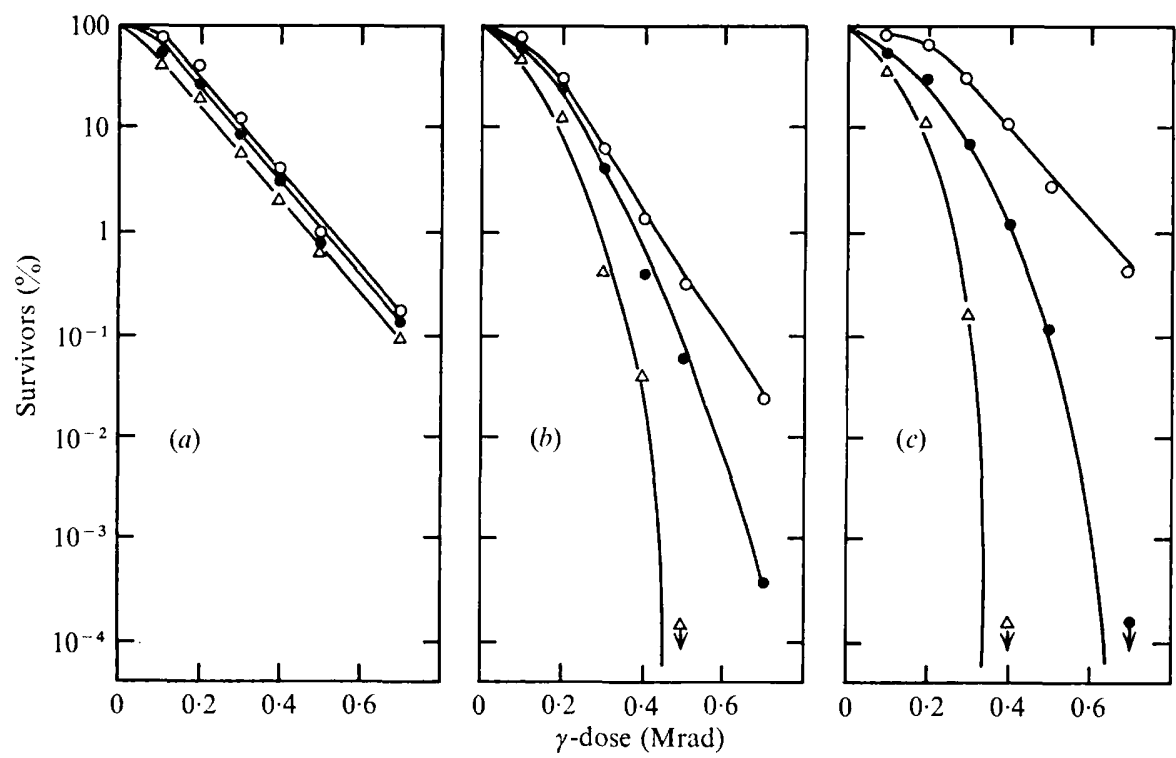

Fig. 6. Influence of temperature on inactivation of spores of Bacillus cereus by $\gamma$-radiation in the presence of potassium iodate. Temperatures during irradiation were $(a)-15^{\circ}$, (b) $2^{\circ},(c) 30^{\circ}$. The aqueous spore suspensions contained about $10^{8} \mathrm{spores} / \mathrm{ml}$. and either no addition $(\mathrm{O})$, or potassium iodate at $100 \mu_{\mathrm{M}}(\ominus)$ or I $\mathrm{mM}(\triangle)$. Arrows indicate no recovery at that level of count.

\section{Table 8. Lethality of iodine for spores of Bacillus cereus at different $p H$ values}

Buffers were sodium phosphate (IO $\mathrm{mM}$ ) with $\mathrm{pH}$ values adjusted as for the radiation experiments (see Table 5). Iodine was dissolved in KI solution $\left(2 \times\right.$ molarity of $\left.\mathrm{I}_{2}\right)$. Spores $\left(\mathrm{I} \cdot 5 \times 10^{8} / \mathrm{ml}\right.$.) were exposed to the reagents in sealed ampoules at room temperature for the indicated times before dilution for viable counts.

\begin{tabular}{|c|c|c|c|c|}
\hline \multirow[b]{2}{*}{$\mathrm{pH}$ value } & \multirow{2}{*}{$\begin{array}{c}\text { Iodine } \\
\text { concentration }\end{array}$} & & \multicolumn{2}{|c|}{$\begin{array}{l}\text { Survivors (\%) following incubation } \\
\text { in iodine solution for: }\end{array}$} \\
\hline & & I h. & $4 \mathrm{~h}$. & $24 \mathrm{~h}$. \\
\hline 3.0 & $\begin{array}{r}500 \mu \mathrm{M} \\
50 \mu \mathrm{M}\end{array}$ & $\begin{array}{l}0 \cdot 17 \\
85 \cdot 0\end{array}$ & $\begin{array}{l}0.0024 \\
48 \cdot 5\end{array}$ & $<\begin{array}{r}10^{-4} \\
6.65\end{array}$ \\
\hline $5 \cdot 0$ & $\begin{array}{r}500 \mu_{\mathrm{M}} \\
50 \mu_{\mathrm{M}}\end{array}$ & $\begin{array}{l}0.063 \\
104\end{array}$ & $\begin{array}{l}0.0079 \\
\text { I } 21\end{array}$ & $\underset{101}{<10^{-4}}$ \\
\hline $7 \cdot 0$ & $\begin{array}{r}500 \mu \mathrm{M} \\
50 \mu \mathrm{M}\end{array}$ & $\begin{array}{l}0.16 \\
103\end{array}$ & $\begin{array}{l}0.024 \\
116\end{array}$ & $<\mathrm{IO}^{-4}$ \\
\hline $9 \cdot 0$ & $\begin{array}{r}500 \mu \mathrm{M} \\
50 \mu \mathrm{M}\end{array}$ & $\begin{array}{l}0.24 \\
124\end{array}$ & $\begin{array}{l}0.021 \\
102\end{array}$ & $\begin{array}{r}<10^{-4} \\
73.5\end{array}$ \\
\hline
\end{tabular}




\section{Effect of $\gamma$-radiation plus potentiators on spores other than Bacillus cereus $P X$}

Spores of Bacillus coagulans, B. subtilis, B. polymyxa and B. cereus strain T were all killed more readily by $\gamma$-radiation when in the presence of IAM and $\mathrm{KIO}_{3}$, though the effectiveness of the potentiators differed quantitatively according to the spores used.

\section{DISCUSSION}

A variety of halogen compounds could potentiate the lethal action of $\gamma$-radiation for spores of Bacillus cereus and, in addition to toxic chemicals like IAM, relatively innocuous compounds like L-thyroxine, diiodo-L-tyrosine, iodide and iodate could act as potentiators. In homologous series potentiator activity decreased in the order $\mathrm{I}>\mathrm{Br}>\mathrm{Cl}$ and $\mathrm{F}$, the latter two being essentially inactive. The potentiation was probably due mostly to halogen or halogen-free radicals rather than thiol reactivity of some of the reagents, because the two reagents for thiols, $p \mathrm{CMB}$ and NEM, did not potentiate action of radiation on spores whereas iodide and bromide, which one would not expect to react with thiols, did potentiate. In contrast, certain radiationresistant vegetative bacteria could be inactivated readily by ionizing radiation in the presence of reagents for thiols (Bridges, I968). For example, $N$-ethylmaleimide was a potentiator for the radiation inactivation of Escherichia coli and a Pseudomonas species (Bridges, I 96I, 1962), as was p-hydroxymercuribenzoate for Micrococcus radiodurans, E. coli and Sarcina lutea (Bruce \& Malchman, 1965). Further study suggested that thiol reactivity was not the sole attribute of effective potentiators (Barnes, Ashwood-Smith \& Bridges, I969; Mullenger \& Ormerod, 1969). These reagents may in fact act by being particularly efficient electron acceptors, reacting with short-lived hydrated electrons to form negatively charged radicals which are longer-lived and more able to damage vegetative bacteria (Adams \& Dewey, I963; Adams \& Cooke, I969); however, such radicals, at least from NEM and $p \mathrm{CMB}$, were negligibly lethal for spores.

Quenching by histidine, which would react with iodine (Schramm, I964) but not with free IAM, supports the hypothesis that potentiation of the radiation inactivation of spores was caused by halogen-free radicals. This hypothesis is also compatible with the observed convex shape of the survivor curves of spores irradiated in water plus IAM or iodate, which indicated an effect which was cumulative with radiation dose. Loss of potentiator activity at $-15^{\circ}$ strongly implicated free radical intermediates. The low content of organic matter in fresh well-cleaned spore suspensions probably accounted for their greater sensitivity to potentiators than old less-clean suspensions. The effect of $\mathrm{pH}$ value was interesting in that potentiation was greatest at low $\mathrm{pH}$ values when no rich medium was present, but in the presence of medium the potentiator was more effectively antagonized at low $\mathrm{pH}$ value. Presumably the toxic radiation product(s) reacted more effectively at low than at high $\mathrm{pH}$ values with either medium constituents ('antagonism') or with the spores ('potentiation'). The reason for antagonism of potentiators by sodium phosphate buffers is not clear, because antagonism did not depend on $\mathrm{pH}$ value alone.

Iodine alone killed spores during the same periods of time involved in the radiation experiments $(<3 \mathrm{~h}$.). Could it be that free iodine formed by radiolysis partly caused the observed potentiation? Antagonism of the potentiation by histidine is compatible 
with the toxic agent being free iodine. A comparison of Tables 5 and 8, however, shows that the lethal effect of the most effective potentiators (see, for example, $0 \cdot{\mathrm{I} \mathrm{mM}-\mathrm{KIO}_{3}}$ in Table 5) was too great to be solely accounted for by the equivalent amount of iodine, even assuming stoichiometric yield of free halogen $(50 \mu \mathrm{M}$, see Table 8$)$ from the potentiator during irradiation. Furthermore, irradiation of potentiator solutions at their effective concentrations did not make them subsequently toxic to spores, as one would have expected had sufficient stable iodine molecules been formed. The results therefore suggested that some further radiation product was involved in killing spores, most probably a halogen-containing free radical such as was proposed by Dewey \& Michael (1965) to explain potentiation of the radiation inactivation of Micrococcus radiodurans and other vegetative bacteria by IAM. Indeed, study of the effect of free radical reactants on potentiation of radiation inactivation'of $M$. sodonensis by iodide suggested that the responsible radicals were $\mathrm{I}^{\cdot}$ and/or $\mathrm{I}_{2}^{-}$(Mullenger, Singh, Ormerod \& Dean, 1967), formed by reaction of $\mathrm{I}^{-}$ions with $\mathrm{OH}$ radicals produced by radiolysis of water (Sworski, 1955; Dainton \& Peterson, 1962).

The enhancing effect of halides and halogenophenols on the lethal action of ionizing radiation for vegetative bacteria and yeasts was studied extensively by Namiki and Matsuyama and their colleagues. Halogenophenols were effective in the decreasing order $\mathrm{I}>\mathrm{Br}>\mathrm{Cl}$, as in this study, and monosubstituent positions in the order $p->m$ - $>o$ - (Matsuyama, Namiki, Okazawa \& Kaneko, 1963). In contrast, we found $o-, m$ - and $p$-iodobenzoic acids to be about equally effective as potentiators with spores. Their data suggested that death of Escherichia coli irradiated plus halogenophenols resulted largely from indirect action, including toxic free radicals and phenols formed by radiolysis (Namiki, Matsuyama, Okazawa \& Kaneko, 1963). Relative resistance of spores to phenols may explain responses different from those obtained with vegetative cells. High concentrations of $\mathrm{NaCl}($ e.g. $10 \%$ w/v) enhanced the lethality of $\gamma$-radiation for $E$. coli (Matsuyama, Okazawa, Namiki \& Sumuki, 1960) partly, but not solely, because of increased sensitivity of irradiated cells to high concentrations of $\mathrm{NaCl}$ compared with unirradiated cells (Okazawa, Namiki, Yamashita \& Matsuyama, 1960). Study of other halides showed that iodide and bromide were more effective than chloride as potentiators of the radiation inactivation of $E$. coli (Namiki, Okazawa \& Matsuyama, 196I) and iodate was a particularly effective potentiator (Kada, 1969): as with spores, the halides acted most effectively at low $\mathrm{pH}$ values and, it was postulated, probably via the agency of reactive free radicals.

Potentiation of radiation inactivation of such dormant forms as spores is certainly distinct from the potentiation caused by halogenated pyrimidines and related compounds in actively growing bacterial or mammalian cells (Vermund \& Gollin, 1968). In such instances potentiation depends on incorporation of the metabolite into cell macromolecules. It is likely that in spores irradiated in the presence of diverse iodine and bromine compounds the lethal damage is more directly inactivation of enzyme(s) critical in spore germination (Gould, 197I), rather than damage to deoxyribonucleic acid or repair processes such as may result from ionizing radiation alone. The sites of lethal damage in similarly irradiated vegetative bacteria are not yet known with certainty.

The author is grateful to Dr T. A. Roberts for radiation facilities, and to Miss Caroline V. Martindale and Mr A. K. Jackson for efficient technical assistance. 


\section{REFERENCES}

ADAMs, G. E. \& CoOKE, M. S. (I969). Electron-affinic sensitization. I. A structural basis for chemical radiosensitizers in bacteria. International Journal of Radiation Biology 15, 457-47I.

Adams, G. E. \& Dewey, D. L. (1963). Hydrated electrons and radiobiological sensitization. Biochemical \& Biophysical Research Communications 12, 473-477.

Barnes, J. H., Ashwood-Smith, M. J. \& Bridges, B. A. (1969). Radiosensitization of bacterial cells by carbonyl compounds. International Journal of Radiation Biology 15, 285-288.

BRIDGes, B. A. (1961). The effect of $N$-ethylmaleimide on the radiation sensitivity of bacteria. Journal of General Microbiology 29, 467-472.

BRIDGES, B. A. (1962). The chemical sensitization of Pseudomonas species to ionizing radiation. Radiation Research 16, 232-242.

BRIDGES, B. A. (1968). Sensitization of organisms to radiation by sulphydryl-binding agents. Advances in Radiation Biology 3, 70-94.

BRUCE, A. K. \& MAlChMAN, W. H. (1965). Radiation sensitization of Micrococcus radiodurans, Sarcina lutea, and Escherichia coli by $p$-hydroxymercuribenzoate. Radiation Research 24, 473-48I.

Dainton, F. S. \& Peterson, D. B. (1962). Forms of $\mathrm{H}$ and OH produced in the radiolysis of aqueous systems. Proceedings of the Royal Society A 267, 443-463.

Dean, C. J. \& AleXander, P. (1962). Sensitization of radioresistant bacteria to X-rays by iodoacetamide. Nature, London 196, 1324-1326.

Dean, C. J. \& Alexander, P. (1965). The sensitization of bacteria to X-rays by iodoacetamide and related compounds. Progress in Biochemical Pharmacology 1, 46-5I.

Dewey, D. L. \& Michael, B. D. (1965). The mechanism of radiosensitization by iodoacetamide. Biochemical \& Biophysical Research Communications 21, 392-396.

FARKAS, J. \& KIss, I. (1965). Observations on biochemical changes in irradiated spores of Bacillus cereus. Acta biologica Academiae scientiarum hungaricae 12, 15-21.

GouLD, G. W. (I970). Mechanism of the inhibition of germination of bacterial spores by $\gamma$-irradiation in the presence of iodoacetamide and iodate. Journal of General Microbiology 64, 30I-309.

KADA, T. (1969). Radiosensitization by potassium iodate and related compounds. International Journal of Radiation Biology 15, 271-274.

Matsuyama, A., Namiki, M. \& OkazaWa, Y. (1967). Alkali halides as agents enhancing the lethal effect of ionizing radiations on micro-organisms. Radiation Research 30, 687-70I.

MatsuYama, A., Namiki, M., OkaZaWA, Y. \& Kaneko, I. (1963). Synergistic actions of halogenophenols on radiation inactivation of micro-organisms. Agricultural \& Biological Chemistry 27, 349-357.

Matsuyama, A., Okazawa, Y., Namiki, M. \& Sumuki, Y. (1960). Enhancement of radiation lethal effect on micro-organisms by sodium chloride treatment during irradiation. Journal of Radiation Research I-2, 98-I06.

MULLENGER, L. \& ORMEROD, M. G. (1969). The radiosensitization of Micrococcus sodonensis by $N$-ethyl maleimide. International Journal of Radiation Biology 15, 259-269.

Mullenger, L., Singh, B. B., Ormerod, M. G. \& Dean, C. J. (1967). Chemical study of the radiosensitization of Micrococcus sodonensis by iodine compounds. Nature, London 216, 372-374.

Namiki, M., Matsuyama, A., Okazawa, Y. \& Kaneko, I. (1963). Some aspects of synergistic actions of halogenophenols on radiation lethal effect. Agricultural \& Biological Chemistry 27, 359-365.

Namiki, M., OkaZawa, Y. \& Matsuyama, A. (196I). Combined effects of radiation and inorganic reagents during irradiation on radiosensitivity of bacterial cells. Agricultural \& Biological Chemistry 25, I08-I I 4.

Okazawa, Y., Namiki, M., Yamashita, S. \& Matsuyama, A. (1960). Enhancement of overall lethal effect of ionizing radiations on micro-organisms by sodium chloride. Bulletin of the Agricultural Chemistry Society of Japan 24, 235-242.

Schramm, M. (1964). Unmasking of sulphydryl groups in pancreatic $\alpha$-amylase. Biochemistry 3, I 23 I1234.

SwORSKI, T. J. (1955). Yields of hydrogen peroxide in the decomposition of water by cobalt $\gamma$-radiation. II. Effect of chloride ion. Radiation Research 2, 26-32.

Vermund, H. \& Gollin, F. F. (1968). Mechanisms of action of radiotherapy and chemotherapeutic adjuvants. A review. Cancer 21, 58-76. 